\title{
Seminario interno de profesores 2007. ¿Afirmaciones absolutas en una cultura relativista?
}

El seminario interno de profesores de la Facultad de Teología, realizado durante los meses de marzo a octubre de 2007, tuvo como tema convocador: “¿Afirmaciones absolutas en una cultura pluralista?". Esta problemática busca hacerse cargo, por un lado, de la tensión que atraviesa a la automanifestación de Dios en la historia, en que irrumpiendo en ella, la asume y la hace capax revelandi Dei. Tensión que es asumida y radicalizada en la Encarnación, en que el Verbo eterno de Dios "haciéndose carne, se hizo también historia y cultura" (Discurso inaugural de Benedicto XVI a la Conferencia de Aparecida). Así no solo el ser humano sino que la historia y la creación entera devienen, de una manera inédita hasta entonces capax Dei. Y por otro, esta problemática busca confrontar el quehacer teológico -culturalmente situado y condicionado en su ejecución- con la pretensión de absolutez salvífica del anuncio de Jesús y la Buena Noticia de su Resurrección: asume todo el ser humano y es para todos los seres humanos. Esta pretensión se ve, sin duda, enriquecida y al mismo tiempo desafiada en sus posibilidades de sentido al situarla en un contexto cultural y religioso marcado por la pluralidad y la diversidad.

En este número se recogen las 10 sesiones en que profesores de nuestra facultad abordaron esta cuestión desde sus ámbitos de enseñanza y de investigación específicos. En una primera sección -de tipo fundamental- se ponen las bases que permiten entender la cuestión. Esta es iluminada desde un doble ángulo: Desde la filosofía: "Lo absoluto y lo relativo. Aproximación hermenéutica", del profesor Sergio Silva, ss.cc., y “¿Cómo hacer afirmaciones con pretensiones de universalidad a partir de acontecimientos contingentes? El ejemplo de Cristo en la filosofía", del profesor Carlos Casale. Desde la exégesis y teología bíblica: "Verdad absoluta desde el libro del Éxodo: el nombre divino", del profesor Andrés Ferrada.

En un segundo momento se recogen las ponencias en que la problemática del seminario es entendida en y desde ángulos y contextos específicos del quehacer teológico: Desde la cristología en sus inicios: "El carácter universal, único y definitivo de Jesús de Nazaret en los inicios de la cristología”, del profesor Samuel Fernández, y desde la cristología situada en contexto latinoamericano: "La cristología latinoamericana de Jesús crucificado a Cristo resucitado". Luego, se ahonda esta problemática, desde el diálogo de la teología al interior de ella misma, con sus instancias de reflexión propias: "Escuchar devotamente, custodiar celosamente y explicar fielmente lo transmitido ( $D V 10)$ ". Afirmaciones definitivas y lo relativo en el magisterio, del profesor Mons. Andrés Arteaga, y "Formulación de absolutos en teología moral: tres casos", del profesor Pablo Concha, s.j. Y desde el diálogo de la teología con las culturas latinoamericanas expresadas tanto en su elaboración teológica propias: "Cristo liberador, mediador absoluto del reino de Dios", de Jorge 
Costadoat, s.j., como con su literatura: "El 'Dios' huidizo de los escritores", del profesor Alberto Toutin, ss.cc.

Y una tercera sección de tipo más recapitulativo y sistemático, del camino recorrido durante el año: "Absolutez y relatividad del cristianismo", del profesor Juan Noemi, y "Analogia donationis, La teología de lo absoluto en la obra de Hans Urs von Balthasar", de la profesora Anneliese Meis, ssps.

La variedad de perspectivas de análisis acentúa los distintos matices del problema abordado. Y a la vez es decidora de una toma de conciencia-siempre por hacer- en teología en primer lugar de la relacionalidad relativa del objeto de su quehacer: Dios trino que en un éxodo permanente viene al encuentro del hombre, asumiendo su historia y abriéndola a su consumación definitiva. Y al mismo tiempo, toma de conciencia de la relatividad crucificante de su propio quehacer en que sus condiciones de acceso a Dios, de inteligibilidad del mismo así como las afirmaciones que dan cuenta de su presencia y acción en el mundo están culturalmente mediadas. Humana y divinamente, en perspectiva cristiana no puede ser de otro modo. Esperamos que el conjunto de estos artículos transmitan al lector la actualidad del tema abordado, dibuje sus aristas problemáticas y sugieran caminos posibles de sentido.

ANNELIESE MEIS

y Alberto TOUtin 